\title{
Is conscientious objection incompatible with healthcare professionalism?
}

\author{
Mary Neal ${ }^{1}$ and Sara Fovargue ${ }^{2}$
}

Is conscientious objection (CO) necessarily incompatible with the role and duties of a healthcare professional? An influential minority of writers on the subject think that it is and make various types of claim about the source of the incompatibility. In this paper, we begin by outlining the positive case for accommodating $\mathrm{CO}$, before addressing one particular type of incompatibility claim, namely that $\mathrm{CO}$ is fundamentally incompatible with proper healthcare professionalism. The attitude of the conscientious objector, it is claimed, exists in opposition to the sort of disposition (attitudes and underlying character) that we are entitled to expect from a 'good' healthcare professional. We begin here by asking whether this claim is true in principle: what is the disposition of a 'good' healthcare professional, and how does CO align with or contradict it? Having concluded that, at least in principle, $\mathrm{CO}$ need not contradict or undermine good professionalism, we move on to consider practical compatibility, acknowledging that this will involve the identification of appropriate limits on the exercise of $\mathrm{CO}$ and considering briefly what those limits might be. Ultimately, we reject the suggestion that CO is fundamentally incompatible - either in principle or in practice - with good healthcare professionalism.

Keywords: conscientious objection, healthcare professionalism, incompatibility thesis

\section{The positive case for accommodating conscience}

One of the main ways of making a positive case for $\mathrm{CO}$ is to point to the value of 'integrity' and argue that accommodating $\mathrm{CO}$ is essential to the maintenance of the moral or personal integrity of the individual professional (see, e.g. Wicclair, 2000; Brock, 2008; and Antommaria,

\footnotetext{
${ }^{1}$ University of Strathclyde, School of Law

${ }^{2}$ Lancaster University, School of Law
} 
2010). ${ }^{3}$ The view that conscience and integrity are intimately connected has been described as 'uncontroversial' (Giubilini, 2016: 78) and 'the dominant view' (McLeod, 2012: 161). We acknowledge that there is a strong connection between conscience and integrity (Neal and Fovargue, 2016), but recognizing such a connection merely sets up a conflict. It is still necessary to weigh this interest in the balance against the apparently countervailing interests of othersof a woman in accessing a prompt and hassle-free abortion, for example, or of a health authority in avoiding the management consequences of having to accommodate conscience claims - in order to establish why the 'integrity' interest should prevail. A connection between conscience and integrity does not, of itself, present us with a decisive reason for ensuring protection for the interest on the 'conscience/integrity' side of the conflict.

In most integrity-based accounts, accommodation of $\mathrm{CO}$ tends to be justified by reference to the desirability of healthcare professionals maintaining internal harmony and moral consistency, and avoiding guilt, burnout, and self-betrayal (Cowley, 2016: 260). In contrast with this, we see the major harm of conscience violation as consisting not in the production of negative emotional and psychological states, but in the violence done to individuals as moral agents and to the integrity of their moral agency (Neal and Fovargue, 2016). Individuals do not just happen to be moral agents; they develop agency through a complex process of observation, reflection, and practice. At some point during their moral development, agents also acquire a duty to develop, maintain, and exercise their moral agency; to reflect seriously about moral issues, form judgements about the right way to act, and to act on them. The interest of an individual in being able to do these things is a vital one. As Curlin and colleagues argue, 'acting conscientiously is the heart of the ethical life, and to the extent that physicians give it up, they are no longer acting as moral agents' (2007: 1891).

On our account, the interest an individual has in following her conscience is not primarily in avoiding guilt, burnout and so on, however desirable such avoidance may be. Rather, the critical interest that is at stake in CO (and that is protected by accommodating it) is the interest an individual has in becoming and remaining a functioning moral agent (Neal

\footnotetext{
${ }^{3}$ In a recent article (Ben-Moshe, 2019), Nir Ben-Moshe identifies approaches based on 'respect for integrity' and 'tolerance of different points of view' as the two main ways of justifying CO. Ben-Moshe criticizes both approaches for assuming 'that the truth of claims of conscience is irrelevant to their justification', and (drawing on the moral philosophy of Adam Smith) presents an alternative justification in which a conscience claim should be accommodated if it reflects 'a judgment made from the standpoint of an impartial spectator and thus approximates moral truth to the greatest degree possible'.
} 
and Fovargue, 2016). Arguably, phenomena like moral distress, guilt and burnout are signals that one's moral agency is still functional but that it is under stress. Accommodating CO provides space within which the individual can develop and maintain her identity as a moral agent, and it protects the coherent functioning of her agency by shielding her from forced violations of conscience that sever the link between conscientious reflection and conscientious action. As such, there is something particularly fundamental about the interest that CO protects. An interest in acting conscientiously, understood as an interest in achieving and maintaining one's moral agency, cannot be regarded merely as one more interest to be weighed in the balance.

\section{The incompatibility thesis}

In a 2017 article in the Journal of Medical Ethics, Schuklenk and Smalling argue that '[i]t is implausible that professionals who voluntarily join a profession should be endowed with a legal claim not to provide services that are within the scope of the profession's practice and that society expects them to provide' (2017: 234). They insist that '[m]edical professionals have no moral claim in liberal democratic societies to the accommodation of their individual conscientious objections', and that '[t]o accommodate such objections would subvert some of the very reasons ... why the medical profession was created in the first place' (2017: 240). This is another iteration of the 'incompatibility thesis' advanced in various forms by, for example, Kennedy (1988), Cantor (2009), Giubilini (2014) and Savulescu (2016), and also by Schuklenk writing alone (2015). The essence of the incompatibility thesis is the claim that refusal to participate in particular lawful practices for conscientious reasons is incompatible with the professional responsibilities of healthcare professionals.

We have previously challenged two alternative premises on which the incompatibility thesis might rest: namely, that healthcare ought to be practised value-neutrally, or that the only values that ought to influence the practice of healthcare are those 'internal' to healthcare itself (Neal and Fovargue, 2016). Schuklenk and Smalling's argument, however, is premised on another sort of claim of incompatibility. Reproaching the Canadian Medical Association for permitting its members to follow their consciences without imposing any concomitant obligation on them to consider patients' interests, they describe the Association's attitude as 'quite the opposite of what it means to be a professional, where a promise has been made to 
serve the public good and to serve patient interests first and foremost' (2017: 238). If Schuklenk and Smalling regard prioritizing the interests of objecting healthcare professionals over those of patients as 'the opposite of what it means to be a professional', it follows that they must also regard the prioritizing by individual healthcare professionals of their own moral commitments over the interests of patients in the same way. Their remark that accommodation of CO 'subvert[s] some of the very reasons ... why the medical profession was created in the first place', appears to bear this out. Schuklenk and Smalling appear to see an incompatibility, then, between the attitudes of those who prioritize their consciences over patient interests and the attitude we are entitled to expect from healthcare professionals. This is subtly different from claims about incompatibility that are grounded in 'value neutrality' or 'personal versus professional values', and so it deserves to be scrutinized afresh. This involves asking two distinct questions: one about principle and one about practice.

\section{Is CO incompatible in principle with the attitude of the 'good' healthcare professional?}

As a starting point, we need to ask: what attitude(s) should healthcare professionals embody? One idea that features prominently in the literature is that healthcare professionals ought to be 'altruistic' in their approach to their roles. It has been suggested that '[a]ltruism, the unselfish concern for the welfare of others, has been considered an inherent part of a doctor's profession at least since the Hippocratic oath' (Wicks et al, 2011: d4537). Jones notes that '[p]hysicians' altruism towards their patients and others ... is implicit, rather than explicit, in statements about medical professional values and attitudes', but that the altruistic ideal is nevertheless 'embodied in many cultural stereotypes of the "good doctor"' (2002: 624). Examples of altruistic behaviour in healthcare might include 'continuing to work or providing informal medical advice outside contracted hours, giving free treatment to poor patients in fee for service healthcare systems, and a general willingness to go the extra mile in professional activities' (Jones, 2002: 624).

Some claim that altruism is a 'duty' for healthcare professionals and regard the exercise of $\mathrm{CO}$ as incompatible with this duty. Morrison and Allekotte, for example, advocate limiting $\mathrm{CO}$ explicitly on the basis that '[b]y entering the medical profession, practitioners agree to a set of ethical principles which ensure that they will put the patient's interests before their own' 
(2010: 142). Likewise, Rhodes defends the incompatibility thesis on the ground that '[w]hen a physician chooses to act on his own values instead of honoring his patient's, the physician ... departs from medicine's standard of altruism and violates a crucial tenet of medical ethics that every physician is duty bound to observe' (2006: 78). However, most professional activity cannot be characterized as 'pure' altruism (helping others with no expectation of anything in return). Healthcare professionals are altruistic in the pure sense when they 'go the extra mile', as Jones puts it (2002: 624). This could be by, for example, volunteering to go and help those affected by war, natural disasters, or disease outbreaks, or by agreeing to forego leave in times of emergency, or by stopping to help accident victims while off duty. Healthcare professionals cannot be said, however, to be exhibiting pure altruism when treating patients in the ordinary course of their paid employment.

Related to the idea of altruism, but distinct from it, is the idea of 'service'. For Schuklenk and Smalling, healthcare professionalism entails a willingness to 'serve patient interests first and foremost' (2017: 238), and, writing alone, Schuklenk has stated that '[d]octors are first and foremost providers of healthcare services' (2015: iii). Similarly, Savulescu sees doctors as 'public servants' who ought to suppress moral objections and make themselves available to serve their patients in any way the law permits (2006: 297), and Kennedy exhorts those working in the National Health Service to 'remember the last word of the three, "service", and serve' (1988: 29). Those who adopt the language of 'service' often attribute malign attitudes to those who defend and practise CO; for example, Schuklenk and Smalling describe conscientious refusals as reflecting 'arbitrary dislikes' (2017: 238), and Savulescu claims that they are associated with 'idiosyncratic, bigoted, and discriminatory' medical practice (2006: 297). Similarly, Fiala and Arthur describe CO in medicine as 'dishonourable disobedience' because it 'contravenes the ethical obligation to serve the public' (2014: 19, emphasis added).

Now this might be because, whereas altruism implies selfless beneficence, service can have contractual/commercial connotations, implying that since healthcare professionals are drawing a wage, they should be willing to perform all tasks that might reasonably form part of their job description. Alternatively, 'service' can have connotations of subservience ('master and servant'), which might imply that the business of healthcare professionals 'putting patients first' is a matter of obedience or deference. But neither of these is an appropriate way to understand the healthcare professional-patient relationship. Indeed, Wicclair warns against 'the implausible absolutist view that the healing-related interests of patients always trump 
physician interests' (Wicclair, 2008: 176). Likewise, Bulger, while noting that '[a] special commitment to serving other people is an essential part of the ethos of the profession of medicine and presumably of each of that profession's practising members', nevertheless points out that:

This special commitment does not mean that the doctor must work 90 or 120 hours a week; it does not mean that the doctor must suffer a ruination of any or all nonprofessional responsibilities, such as the family or civic or church activities. It simply acts to define the foundation of the relationship when there is an interaction between doctor and patient. (1987: 114)

Since attitudes (altruistic, service-oriented, or otherwise) are aspects of character and can be understood only in that context, the more fundamental question seems to be 'what kind of character will the good healthcare professional possess?'

There is some convergence in the literature around the idea of trustworthiness being a primary moral attribute required by those in the healthcare professions. For example, Beauchamp and Childress contend that a 'climate of trust is essential in medical and health care, where patients are vulnerable and must put themselves in the hands of health care professionals' (Beauchamp and Childress, 2013: 39). They have also regarded it as the defining moral characteristic of the encounter that forms the heart of medicine, and suggested that: 'the physician is ... necessarily a trustee for the patient's medical welfare' (2001: 312).

Pellegrino and Thomasma observe that '[t]rust is ineradicable in human relationships' (1993: 65),, and the doctor-patient relationship has been described as 'a paradigm of a relationship of trust' (O'Neill: 17; also, Pellegrino and Thomasma, 1993: 68). This is because within the doctor-patient encounter ' $[\mathrm{w}] \mathrm{e}$ expect to open the most private domains of our bodies, minds, and social and family relationships to [the professional's] probing gaze. Our vices, foibles, and weaknesses will be exposed to a stranger' (Pellegrino and Thomasma, 1993: 68). Thus, '[f]rom the very first moment, the patient performs an act of trust' (Pellegrino and Thomasma, 1993: 68).

Although trust is 'a theme with ancient roots' (Saad, 2018), it is important to clarify what we mean when we use the term in this context, since the 'traditional model of the trusting doctor-patient relationship has been subject to multiple criticisms for many years' (O'Neill, 
2002: 17). One concern is around the deep association between trust and medical paternalism; as O’Neill has observed:

[d]octor-patient relationships were viewed as relationships of trust only because a paternalistic medicine was assumed, in which the dependence of patients on professionals was generally accepted. The traditional doctor-patient relationship, so its critics claim, may have been one of trust, but not of reasonable trust. Rather, they claimed, patients who placed their trust in doctors were like children who initially must trust their parents blindly. Such trust was based largely on the lack of any alternative. (2002: 18)

This calls to mind Cassell's remark that '[s]ick persons ... are people who are forced to trust' (1991: 76, emphasis added).

Although Katz agrees that 'traditional professional notions of trust are based on the wrong model', a deeply paternalistic one in which patients, conceived as utterly dependent, are expected to display an infantilizing 'basic trust' (2002: 100), this does not mean that trust is not 'an essential ingredient' in doctor-patient interactions., Rather, 'a new kind of trust' based on 'the confident and trusting expectation that physicians will assist patients to make their own decisions' is required (Katz, 2002: 101-102, emphasis added). This means that, as O'Neill puts it, 'trust is properly combined with patient autonomy' (2002: 19), since '[t]he only trust that is well-placed is given by those who understand what is proposed, and who are in a position to refuse or choose in the light of that understanding' (2002: 18).

Zaner, too, discusses the role of trust against the background of the shift from a beneficence-based model of the therapeutic relationship to an autonomy-based model understood largely in terms of the patient's 'rights' and 'entitlements' (2015: 78-79). He cautions that although the idea of trust tends to be 'suppressed' in narratives that prioritise autonomy, it is no less a 'sine qua non' in autonomy-based framings of healthcare ethics (albeit more implicitly so) because of the inescapable role of trust in critical processes like confidentiality and informed consent (2015: 79). Indeed, informed consent has been described as 'the modern clinical ritual of trust' (Wolpe, cited in O'Neill, 2002, 19). Ultimately, Zaner concludes that "autonomy" cannot replace trust in any sense' (2015: 79, emphasis added). 
Given the above, the 'relationship of trust and confidence' must be conceptualised in a way that avoids problematic paternalism but also acknowledges the continued centrality of trust in autonomy-based approaches to healthcare. In addition, in view of the discussion of 'service' and 'altruism' above, our understanding of trust must avoid reducing healthcare professionals to functionaries who exist simply to satisfy patient demands. We favour Beauchamp and Childress' definition of trust as 'a confident belief in and reliance on the moral character and competence of another person' (2013: 39), and we agree with them that:

Trust entails a confidence that another will reliably act with the right motives and feelings and in accordance with appropriate moral norms. To be trustworthy is to merit confidence in one's character and conduct. Trustworthiness has the practical outcome of making health care effective. (2013: 40, emphasis in original, references removed)

Beauchamp and Childress are referring here to moral trustworthiness and not only to trust in clinical competence. This is important because 'medicine is, at its center, a moral enterprise grounded in a covenant of trust' (Crawshaw et al, 1995, 1553), and 'trust has special moral dimensions that are the foundation for professional ethics' (Pellegrino and Thomasma, 1993: $67)$.

A morally trustworthy person is someone we can rely upon because she thas an ingrained motivation and desire to perform right actions' (Beauchamp and Childress, 2009: 33). In other words, moral trustworthiness presupposes the proper functioning of one's moral agency. This brings us back to the claim that forcing healthcare professionals to compartmentalize their moral commitments, and live parallel 'professional' and 'personal' moral lives in which they apply contradictory sets of values, is liable to undermine and erode agent-integrity. Accommodating $\mathrm{CO}$ is necessary to preserve the agent-integrity of the individual, because when agent-integrity is undermined, so is moral trustworthiness, and with it, good professionalism.

Having focussed on the importance of trust in the doctor-patient relationship, it is also important to acknowledge that in modern healthcare practice, many professional-patient interactions will take place between people who have no ongoing relationship. Often, a patient will be greeted by 'not a known and trusted face, but teams of professionals who are neither names nor faces, but as the title of one book aptly put it, strangers at the bedside' (O'Neill, 
2002: 20). A number of NHS initiatives have aimed to address this, including the 'Hello my name is' campaign ("A campaign for more compassionate care") which emphasizes the importance of using first names in professional-patient conversations. ${ }^{4}$

As patients are more likely nowadays to encounter teams of healthcare professionals, in many cases there can be no question of personal knowledge of, and trust in, the moral character of particular individuals. But this does not mean that patients no longer need to rely on the moral trustworthiness of those who provide their care. It is not our argument that CO must be accommodated because patients will otherwise spot particular examples of moral inconsistency and cease to trust particular professionals. Rather, we are concerned that failing to accommodate $\mathrm{CO}$ will lead to the undermining of agent-integrity, moral trustworthiness and good professionalism even if patients are unaware of it. We are primarily concerned with the actual trustworthiness of professionals, rather than the feelings of confidence to which such trustworthiness gives rise, although we acknowledge that both are important.

Ironically, those (like Schuklenk, Smalling and Kennedy) who argue loudest for the elimination of 'private' values from healthcare are often also particularly insistent that healthcare professionals must embody appropriate attitudes, be 'altruistic', and/or 'serve' (Schuklenk and Smalling, 2017; Schuklenk, 2015; Kennedy, 1988). Altruism and selflessness are not simply standards of professional behaviour that can be learned at medical school, however. They are virtues, excellences of character that develop gradually through learning and practice, in the context of moral relationships/communities, ideally beginning in early childhood (Thompson, 2014). Once acquired, virtues become fundamental aspects of one's moral character: as Hursthouse puts it, a virtue is 'a disposition that is well entrenched in its possessor and, as we say, "goes all the way down"' (Hursthouse, 2006). As such, it is unreasonable to expect to be able to rely on a healthcare professional's altruism and selflessness while simultaneously insisting upon the fragmentation of their character into 'public' and 'private' compartments, and demanding that 'private values', even where they are a key source of the relevant virtues, are eliminated from professional role-performance in healthcare.

\section{Is CO incompatible in practice with 'good' healthcare professionalism? The limits of accommodation}

\footnotetext{
${ }^{4}$ See https://www.hellomynameis.org.uk/
} 
We have argued that there is no incompatibility in principle between the accommodation and exercise of CO and 'good' healthcare professionalism. On the contrary, the most indispensable personal attribute of the good healthcare professional (apart from clinical competence) is moral trustworthiness, and CO is not only 'not incompatible' with moral trustworthiness, but is both a recognition of its importance and a practical safeguard for ensuring it. Ultimately, however, the compatibility of $\mathrm{CO}$ and healthcare professionalism depends not only on there being no principled opposition between the two, but also on an ability to set appropriate limits on $\mathrm{CO}$ in practice. This is because allowing healthcare professionals an unfettered freedom to follow their consciences across the whole range of professional activities would pose insurmountable practical problems for the delivery of healthcare. We are unaware of any scholars who defend unfettered freedom of $\mathrm{CO}$, though some defend a wide-ranging right to refuse (for example, Ancell and Sinnott-Armstrong, 2017). Rather, those in favour of accommodating $\mathrm{CO}$ in healthcare have provided a range of suggestions about the most appropriate way(s) of circumscribing the availability and exercise of CO by healthcare professionals. These include that we ought to limit CO to cases involving 'life issues' (that is, where the objected practice involves the ending of human life); ${ }^{5}$ that we ought to restrict it to a limited range of practices based on some other criterion (see, e.g., Neal, 2019); that the exercise of $\mathrm{CO}$ should be confined to cases in which tests of genuineness and/or reasonableness can be satisfied (for example, Card, 2016 and 2017; Kantymir and McLeod, 2014); and that we ought to make CO available only where the healthcare professional's participation would be 'direct' ${ }^{6}$ These proposals for limiting CO are neither exhaustive nor mutually exclusive.

As there is no scope here to analyse in any depth the strengths and weaknesses of all of these possible ways of limiting the exercise of $\mathrm{CO}$, we will focus on claims that there is a way of testing the genuineness (or 'sincerity') and/or reasonableness of objections and of weeding out those that are found to be insincere or unreasonable. We are particularly interested in these claims because if moral agency and trustworthiness are fundamental to healthcare professionalism, as we claim in the previous section, this might seem to entail that if $\mathrm{CO}$ is to be compatible with professionalism, it must pass tests of genuineness/sincerity and

\footnotetext{
${ }^{5}$ This was the approach taken in the recent Conscientious Objection (Medical Activities) Bill [HL] in the UK.

${ }^{6}$ This was the approach taken by the UK Supreme Court in the case of Greater Glasgow Health Board v Doogan and another [2014] UKSC 68.
} 
reasonableness. If trustworthiness is fundamental to healthcare professionalism, and incompatible with deception, then presumably this means that insincere claims of $\mathrm{CO}$, at least, are incompatible with professionalism. Similarly, if $\mathrm{CO}$ is about promoting and protecting the integrity of a healthcare professional's moral agency, then perhaps it is relevant that a wellfunctioning moral agent will arrive at moral conclusions that are reasonable. If someone's moral conclusions are unreasonable, or even verifiably false, then regardless of the fact that their conclusions are sincere, this seems to be a case of agency gone awry, so that we may be doing nothing of value when we 'protect' or 'support' it via CO.

Schuklenk and Smalling acknowledge the considerable academic attention devoted to the issue of appropriately limiting $\mathrm{CO}$, and note that there is some support for the idea of requiring those exercising $\mathrm{CO}$ to meet tests of 'genuineness' and/or 'reasonableness' (see, for example, Card 2016 and 2017). In their view, the only way to establish appropriate limits on the scope of CO would be to test both the genuineness of objections and the truth of the beliefs on which they are based, and accommodate only those claims that pass both of these tests (2017: 236). Ultimately, however, they conclude that 'it is a moot point trying to establish the truth or even plausibility of the views purportedly held by conscientious objectors', and that 'it is also impossible to ascertain whether conscientious objectors actually hold the views they profess to hold' (2017: 236).

We agree with these conclusions, and have previously argued that while we would expect conscientious healthcare professionals to be willing at least to attempt to articulate their objections as a gesture of good faith to the moral community, decisions about whether or not to accommodate their refusal should not hinge on how successfully they do this (Fovargue and Neal, 2015). In particular, we reject any suggestion that the ability to articulate an objection to the satisfaction of a panel in a 'draft board' type scenario should be a prerequisite for $\mathrm{CO}$. For one thing, tests designed to ascertain the genuineness, 'reasonableness' or even 'truth' of an objection might simply privilege more articulate, confident or plausible candidates over those who are less confident in expressing themselves in that kind of context, regardless of the genuineness of their claims (Fovargue and Neal, 2015). This is not to say that dishonesty is no barrier to exercising $\mathrm{CO}$, however. If there is evidence that someone claiming a $\mathrm{CO}$ is being dishonest (for example, that she wishes to avoid participation in abortion because she regards it as menial or distasteful work, and not because of any moral objection - a possibility discussed by Meyers and Woods, 1996), this gives us a 
good reason not to accommodate her refusal. This is because, as we have explained above, CO exists to safeguard agent-integrity, and in the absence of any genuine moral objection to the practice concerned, there can be no risk that performing the practice will violate the agentintegrity of the objector. Where agent-integrity is not truly at stake, there is no need for the protection afforded by CO.

Neither does it seem appropriate to subject views premised on religious or spiritual beliefs (as may often be the case in the context of $\mathrm{CO}$ ) to tests of 'reasonableness'. For example, it would be fruitless to attempt to determine whether the belief of a Catholic midwife that each human embryo and foetus is deliberately created and loved by God, and possesses an immortal soul, is 'reasonable' or 'unreasonable' according to some secular standard or other (Marsh, 2014). ${ }^{7}$ Moreover, since the views at stake in CO are moral views, attempting to assess their 'truth' also seems futile. Moral claims and beliefs may, of course, be grounded in other beliefs which are empirically verifiable. If this is the case, and the underpinning beliefs are shown to be false, this could be relevant to the question of whether CO should be accommodated. But the truth or falsity of moral views themselves cannot be established objectively, even if such views might be objectively true or false in ways we cannot verify.

Nevertheless, Schuklenk and Smalling warn that any criteria other than truth or genuineness will inevitably leave the door open to an arbitrary expansion of the range of actions in respect of which $\mathrm{CO}$ is permitted, with harmful consequences for patients and colleagues (2017: 236). This assertion invites at least three immediate responses. First, Schuklenk and Smalling imply that they would countenance objections whose genuineness and truthfulness could be proven. Yet, as noted already, they say that ' $\mathrm{t}$ ] $\mathrm{o}$ accommodate [conscientious] objections would subvert some of the very reasons ... why the medical profession was created in the first place' (2017: 240), and that healthcare professionals ought always to prioritize patient interests over fidelity to their own moral commitments (something we dispute). How can it be consistent with this position to accommodate any CO at all?

Secondly, proof of 'truth' would have a more far-reaching impact on the debate than Schuklenk and Smalling suppose. In the context of abortion, for example, the relevant belief is usually that abortion is morally-prohibited killing. If it could be proven that this were true (which we agree it cannot), the consequences of that finding would go beyond the

\footnotetext{
${ }^{7}$ We are aware, of course, that the possibility of anti-religious discrimination also arises in this context, due to the religious basis/nature of some conscientious objections. This is not our focus here, however.
} 
permissibility of $\mathrm{CO}$; it would raise serious questions about whether, and in what circumstances, abortion itself could be permitted. For Schuklenk and Smalling, then, it seems that $\mathrm{CO}$ is (hypothetically) permissible only where the moral permissibility of the objected practice is itself in serious doubt. In such circumstances, however, the question would no longer be whether we ought to allow those healthcare professionals who wish not to participate to be exempt; we would, instead, be obliged to give serious consideration to whether the practice itself ought to be permitted. Unfortunately, Schuklenk and Smalling appear to miss this bigger picture. (This issue also needs to be considered in relation to Nir Ben-Moshe's recent suggestion (Ben-Moshe, 2019) that the permissibility of conscience claims can be determined according to how likely they are to embody 'moral truth' (or to be potentially morally true) from the standpoint of an impartial observer.)

Finally, Schuklenk and Smalling claim that any criteria other than truth and genuineness will ultimately make it impossible to exclude 'indefensible' objections, and that:

Regardless of the accommodations that we make today, these can and likely will be challenged time and again by new generations of conscientious objectors. Today it might be abortion and assisted dying, tomorrow it might be the use of the tools of personalised medicine or something else altogether. (Schuklenk and Smalling, 2017: 236)

Although there is no scope to analyse them here, we agree that there are significant problems with each of the limiting strategies most commonly proposed in the academic literature. We have already discussed some of the shortcomings of tests designed to ensure 'genuineness/sincerity' and 'reasonableness/truth'. Limiting CO to 'life issues' is problematic too, because although the taking of human life undoubtedly engages the human conscience in a particularly strong way, or ought to, other issues might also engage conscience seriously enough to pose a threat to agent-integrity. Given that our version of the positive case for CO rests on the value of agent-integrity, it would be illogical for us to restrict the scope of CO to threats of one kind, absent some additional form of justification. Finally, as one of us has argued, the distinction between 'direct' and 'indirect' involvement in a practice or procedure is not an appropriate test for whether or not CO ought to be accommodated (Neal, 2015). 
Despite all of this, we disagree that allowing CO will inevitably oblige us to accept indefensible claims, or to expand indefinitely the range of practices covered by conscience rights. In our view, the idea of 'liminally proper treatment' offers a more promising way of limiting the extent of CO (Fovargue and Neal, 2015; Neal, 2019). The courts in the UK have long recognised that the criminal law of offences against the person contains an exception for 'proper medical treatment'. ${ }^{8}$ This means that intrusions which would ordinarily constitute serious crimes can be lawful if performed by a qualified healthcare professional in the course of proper medical treatment. Most academic commentary about proper medical treatment has, understandably, focused on what makes treatment 'proper' and therefore lawful rather than unlawful (see, for example, Fovargue and Mullock, 2015). However, one of us has argued that within the wider landscape of proper medical treatment it is possible to identify various gradations of properness: most treatment is paradigmatically proper, some is clearly proper, and other treatment is liminally proper. This has been theorized more fully elsewhere (Neal, 2019). What matters for present purposes is that 'liminally proper' treatment is a category of treatment which is proper in a more marginal or tentative sense than usual, - perhaps because it is ethically controversial, or very risky, or directed at producing claimed 'social goods' other than the prevention, cure, or management of disease. Whatever the precise source of the liminality in any given case, liminal properness is always connected to the sense in which healthcare and the professional-patient relationship are ideally 'therapeutic' in nature (Neal, 2019). It occurs where the potential for therapeutic benefit is doubtful or even absent, and where this claimed or acknowledged therapeutic deficiency is compensated by making claims about social or public 'good'. Such claims are always contestable, and when they are used to justify why a practice is 'proper medical treatment' despite having doubtful or no potential for therapeutic benefit, this controversy carries over so that liminally proper treatment is always a site of legitimate debate and disagreement. This makes it appropriate to accommodate CO in relation to it.

Together, we have argued that $\mathrm{CO}$ is unnecessary where a practice falls clearly inside or outside the definition of 'proper medical treatment' (Fovargue and Neal, 2015). This is because provision for $\mathrm{CO}$ exists to protect healthcare professionals against an expectation that they will act in a certain way; if no such expectation exists, there is no need for protection

\footnotetext{
${ }^{8}$ Airedale NHS Trust v Bland [1993] AC 789; R v Brown [1994] 1 AC 212.
} 
against it. Conversely, if there is no controversy surrounding a particular practice, there is no reason to suppose that anyone might need to withdraw from participating in it. Thus, it is appropriate to accommodate $\mathrm{CO}$ only in relation to treatment which, although lawful and accepted as part of medical practice, is proper in a liminal sense.

In response to Schuklenk and Smalling's worry about the uncontrolled expansion of CO, therefore, we argue that there is a coherent and defensible way of limiting the applicability of co. Although the content of the 'liminal' category will undoubtedly change over time, any change will not be a straightforward expansion. On the contrary, as new controversial or risky practices emerge and join the category, other previously liminal practices will exit the liminal realm and join the 'clearly proper' category as they become less risky, or as normalisation makes them uncontroversial. And while some activities may remain controversial over the long term (for example, interventions that involve the ending of life or those perceived as involving preference satisfaction rather than healing), overall, what is 'liminal' will evolve rather than simply expand.

Furthermore, when it is appropriate to accommodate CO, the 'conscientious' nature of the objections being accommodated entails that those who exercise the right to refuse must do so in a way that avoids burdening others beyond what is minimally necessary to avoid serious moral threat (Fovargue and Neal 2015). In our view, the fact that claims of CO express an aspiration to act morally and avoid wrongdoing is key, and we have recognized a range of duties as attaching to the exercise of CO precisely because it expresses this aspiration. These duties represent logical, rather than practical limits on the exercise of CO. Nevertheless, they can provide a basis on which to criticize certain exercises of CO.

Thus, whereas Schuklenk and Smalling interpret CO as expressing 'arbitrary dislikes' (2017: 238), we see it neither as arbitrary nor as anything to do with 'dislike' (other than a dislike of wrongdoing). The upshot of our argument is that it is far from impossible to identify logical limits on the scope of CO; on the contrary, we have summarised two complementary types of logical limit here. First, the accommodation of CO should be limited to liminally-proper treatment. In addition, we can require that the exercise of CO must conform to some basic moral requirements, since whatever else it may do, $\mathrm{CO}$ expresses an aspiration to virtue and good character. 


\section{Conclusion}

Contrary to the claims of CO's most strident critics, we argue that there is no principled or practical reason to regard CO as incompatible with 'good' healthcare professionalism. In terms of principle, the 'relationship founded on trust and confidence' that is central to healthcare presupposes the moral trustworthiness of healthcare professionals, and this, in turn, presupposes the integrity of the professionals' moral agency. Insofar as CO exists to protect this 'agent-integrity', it is not only not incompatible with good healthcare professionalism, but an essential tool for safeguarding it. Within certain limits, when a healthcare professional who routinely serves her patients in numerous ways declines to 'serve' in a particular way because she regards a moral obligation not to do so as binding upon her, she preserves her agentintegrity and her capacity to form relationships of trust and confidence in the future. In our view, trustworthiness and integrity are more fundamental to the professional-patient relationship than a willingness to perform any particular procedure. Furthermore, whereas accommodating CO supports these core professional virtues, compelling participation threatens them. Considering $\mathrm{CO}$ in the light of attitude and character helps to clarify precisely why it must be accommodated.

The compatibility of $\mathrm{CO}$ and healthcare professionalism cannot be established purely at the level of principle; establishing compatibility also requires being able to set appropriate practical limits on the exercise of $\mathrm{CO}$. Although most of the suggestions in the existing academic literature fall short, Schuklenk and Smalling's assertion that no appropriate limits are possible is premature and overly-pessimistic. In our view, the concept of 'liminally proper treatment' can help to map out the territorial extent of CO in healthcare. In addition, we argue that it is possible to recognise certain duties attaching to its exercise which arise naturally out of the 'conscientious' aspect of CO. As such, the project of identifying appropriate parameters for CO is, for us, very much alive.

Schuklenk and Smalling describe those engaged in the search for appropriate limits as engaged in seeking 'compromise', but we do not regard the limits we recommend as a matter of 'compromise'; at least, not in ethical terms. The limits we have proposed arise directly out of a combination of the therapeutic nature of healthcare and the fact that CO expresses an aspiration to act morally (discussed more fully in Fovargue and Neal, 2015). As such, they are principled limits on the accommodation of $\mathrm{CO}$ and not a strategic concession or compromise. 


\section{References}

Ancell, A., and W. Sinnott-Armstrong, 2017. How to Allow Conscientious Objection in Medicine While Protecting Patient Rights. Cambridge Quarterly of Healthcare Ethics. 26(1): 120131.

Antommaria, A. H. M., 2010. Conscientious objection in clinical practice: Notice, informed consent, referral, and emergency treatment Ave Maria Law Review. 9: 81-99.

Beauchamp, T., and J. Childress, 2001. Principles of Biomedical Ethics, $5^{\text {th }}$ edition. New York: Oxford University Press.

Beauchamp, T., and J. Childress, 2009. Principles of Biomedical Ethics, $6^{\text {th }}$ edition. New York: Oxford University Press.

Beauchamp, T., and J. Childress, 2013. Principles of Biomedical Ethics, $7^{\text {th }}$ edition. New York: Oxford University Press.

Ben-Moshe, N., 2019. The truth behind conscientious objection in medicine. Journal of Medical Ethics. 45:404-410.

Brock, D., 2008. Conscientious refusal by physicians and pharmacists: Who is obligated to do what, and why? Theoretical Medicine and Bioethics. 29: 187-200.

Bulger, R. J., 1987. Emerging Unities of the Twenty-first Century: Service as Sacrament, Emotional Neutrality, and the Power of the Therapeutic Word. In RJ Bulger (ed). In Search of the Modern Hippocrates. Iowa City: University of lowa Press, 108-124.

Cantor, J., 2009. Conscientious objection gone awry - Restoring selfless professionalism in medicine. New England Journal of Medicine. 360(15): 1484-1485.

Card, R., 2016. In defence of medical tribunals and the reasonability standard for conscientious objection in medicine. Journal of Medical Ethics. 42(2): 73-5.

Card, R., 2017. The Inevitability of Assessing Reasons in Debates about Conscientious Objection in Medicine. Cambridge Quarterly of Healthcare Ethics. 26(1): 82-96.

Cassell, E. J., 1991. The Nature of Suffering and the Goals of Medicine. New York: Oxford University Press.

Cowley, C., 2016. A defence of conscientious objection in medicine: A reply to Schuklenk and Savulescu. Bioethics. 30(5): 358-364. 
Crawshaw, R., DE Rodgers, ED Pellegrino, et al, 1995. Physician-Patient Covenant. Journal of the American Medical Association. 273(19): 1553.

Curlin, F. A., L. E. Lawrence, and J. D. Lantos, 2007. The Authors Reply. Correspondence: Religion, conscience and controversial practices. New England Journal of Medicine. 356(18): 1889-1892.

Fiala, C., and J. Arthur, 2014. "Dishonourable disobedience"-Why refusal to treat in reproductive healthcare is not conscientious objection. Woman-Psychosomatic Gynaecology and Obstetrics. 1: 12-23.

Fovargue, S., and M. Neal, 2015. 'In Good Conscience': Conscience-Based Exemptions and Proper Medical Treatment. Medical Law Review. 23(2):221-241.

Fovargue, S., and A. Mullock, (eds), 2015. The Legitimacy of Medical Treatment: What Role for the Medical Exception? Oxford: Routledge.

Giubilini, A., 2016. Conscientious objections and medical tribunals. Journal of Medical Ethics. 42(2): 78-79.

Giubilini, A., 2014. The paradox of conscientious objection and the anaemic concept of 'conscience': Downplaying the role of moral integrity in healthcare. Kennedy Institute of Ethics Journal. 24(2): 159-185.

Hursthouse, R., 2006. Are Virtues the Proper Starting Point for Morality? In J Dreier (ed). Contemporary Debates in Moral Theory. Wiley-Blackwell, 99-112.

Jones, R., 2002. Declining altruism in medicine. British Medical Journal 324(7350): 624-5.

Kantymir, L., and C. McLeod, 2014. Justifications for conscience exemptions in health care. Bioethics. 28(1): 16-23.

Katz, J., 2002. The Silent World of Doctor and Patient. Baltimore: Johns Hopkins University Press.

Kennedy, I., 1988. Treat Me Right: Essays in Medical Law. Oxford: Clarendon Press.

Marsh, J., 2014. Conscientious refusals and reason-giving. Bioethics. 28(6): 313-319.

McLeod, C., 2012. Taking a Feminist Relational Perspective on Conscience. In J. Downie and J. J. Llewellyn (eds). Being Relational: Reflections on Relational Theory and Health Law. Vancouver: UBC Press.

Meyers, C., and R.D. Woods, 1996. An obligation to provide abortion services: What happens when physicians refuse? Journal of Medical Ethics. 22(2):115-120. 
Morrison, J., and M. Allekotte, 2010. Duty First: Towards Patient-Centered Care and Limitations on the Right to Refuse for Moral, Religious or Ethical Reasons. Ave Maria Law Review. 9(1): 141.

Neal, M., 2015. When Conscience Isn't Clear: Greater Glasgow Health Board v Doogan and Another [2014] UKSC 68. Medical Law Review. 23(4): 668-682.

Neal, M., and S. Fovargue, 2016. Conscience as Agent-Integrity: A Defence of Conscience-Based Exemptions in the Healthcare Context. Medical Law Review 24(4): 544-570.

Neal, M., 2019. Conscientious Objection, 'Proper Medical Treatment', and Professionalism: The Limits of Accommodation for Conscience in Healthcare. In J. Adenitire (ed). Religious Beliefs and Conscientious Exemptions in a Liberal State. Oxford: Hart Publishing.

Pellegrino, ED., and DC. Thomasma, 1993. The Virtues in Medical Practice. New York: Oxford University Press.

Ramsey, P., 2002. The Patient as Person. Second edition. New Haven: Yale University Press.

Rhodes, R., 2006. The ethical standard of care. American Journal of Bioethics. 6(2): 76-78.

Saad, T., 2018. The history of autonomy in medicine from antiquity to principlism. Medicine, Health Care and Philosophy. 21(1): 125-137.

Savulescu, J., 2006. Conscientious objection in medicine. British Medical Journal. 332(7536): 294-297.

Schuklenk, U., and R. Smalling, 2017. Why medical professionals have no moral claim to conscientious objection accommodation in liberal democracies. Journal of Medical Ethics. 43(4): 234-240.

Schuklenk, U., 2015. Conscientious objection in medicine: Private ideological convictions must not supercede public service obligations. Bioethics. 29(5): ii-iii.

Thompson, R. A., 2015. The Development of Virtue: A Perspective from Developmental Psychology. In NE Snow (ed). Cultivating Virtue: Perspectives from Philosophy, Theology, and Psychology. New York: Oxford University Press, 279-306.

Wicclair, M. R., 2000. Conscientious objection in medicine. Bioethics. 14: 205-227.

Wicclair, M. R., 2008. Is conscientious objection incompatible with a physician's professional obligations? Theoretical medicine and bioethics. 29(3): 171-185.

Wicks, L., S. Noor, and V. Rajaratnam, 2011. Altruism and Medicine. BMJ. 343: d4537. 
Wolpe, P. R., 1998. The Triumph of Autonomy in American Bioethics: A Sociological View. In R. DeVries and J. Subedi (eds). Bioethics and Society: Constructing the Ethical Enterprise. Englewood Cliffs, NJ: Prentice-Hall, 38-59.

Zaner, R., 2015. A Critical Examination of Ethics in Health Care and Biomedical Research: Voices and Visions. New York: Springer. 